\title{
EFL College Students' Perceptions of the Difficulties in Oral Presentation as a Form of Assessment
}

\author{
Nowreyah A. Al-Nouh ${ }^{1}$, Muneera M. Abdul-Kareem ${ }^{2} \&$ Hanan A. Taqi ${ }^{1}$ \\ ${ }^{1}$ English Department, College of Basic Education, Kuwait City, Kuwait \\ ${ }^{2}$ College of Education, Kuwait University, Kuwait City, Kuwait \\ Correspondence: Nowreyah Al-Nouh, DHL Express - Head Office, Ardhiya Industrial Area. Post Code: 13126. \\ Kuwait City, Kuwait. Tel: 965-99112672. E-mail: nowreyah2008@hotmail.com \\ Received: December 21, 2014 \\ Accepted: January 11, 2015 \\ Online Published: January 12, 2015 \\ doi:10.5430/ijhe.v4n1p136 \\ URL: http://dx.doi.org/10.5430/ijhe.v4n1p136
}

\begin{abstract}
Oral presentation skills are considered one of the most important proficiencies needed for higher education and future careers. Thus, the present study is interested in eliciting English as a Foreign Language (EFL) college students' perceptions of the difficulties they face in oral presentation as a form of assessment. Participants were 500 female EFL college students from different grade levels enrolled in a four-year pre-service teacher education program at the College of Basic Education (CBE) in Kuwait City, Kuwait. A five-point Likert Scale questionnaire was used and divided into three main sections: personal traits, oral presentation skills, and instructor and audience. Independent variables measured were students' ages, year at college, Grade Point Average (GPA), and nationality. In addition, a structured interview to solicit instructors' opinions was carried out. Results showed students' perceptions of the difficulties they experienced at a medium level $(\mathrm{M}=3.10)$. However, significant differences in the results were found when students' nationalities and GPAs were taken into account.
\end{abstract}

Keywords: Oral presentation, EFL students, Oral assessment, College students' perceptions, Classroom oral assessment

\section{Introduction}

In spite of a technology-driven society, the ability to communicate orally continues to be an essential skill for students at school and university. Summative assessment, the end-of-term examination of knowledge, has traditionally taken the form of written essays in higher education. While moving away from an exclusive reliance on one form of assessment, learning has evolved as the result of many factors. First, students need, in addition to academic growth, to be equipped for the world of work through the development of sufficient skills such as communication, for which alternative forms of assessment are required. Second, students need to experience a variety of assessment methods that take account of their different learning styles and that allow them to demonstrate their abilities in multiple ways (Quality Assurance Agency for Higher Education, 2006; Irvine, 2012). One way of assessing proficiency in communication is through oral presentations.

Oral presentation, according to Levin and Topping (2006), is planned and practiced speech that is not memorized or read from notes but is introduced by a presenter to an audience. Joughin (2007) adds that we can look at oral presentation from three perspectives: presentation as a transmission of the ideas of others to a passive audience with anxiety at a low level, presentation as an imparting of the material studied from which students seek to make their own meanings from the ideas of others; and presentation as a position to be disputed and defended by persuading the audience. In the second perspective, the audience is actively judging students' performances, and students reply to audience questions. Hence, students experience some stress. In the third perspective, students are aware that they are the focus of attention, which creates even more pressure than in the first two situations.

Although oral presentations have been extensively researched, most of the earlier research looked at them in the context of other activities (Akindele \& Trennepohl, 2014), and a large number of studies investigated the effect of anxiety on oral performance (Joughin, 2007). Some studies looked at student opinions of oral presentations compared with written assignments (Akindele \& Trennepohl, 2014), others on how competence is compared to performance in oral presentations (Alwi \& Sidhu, 2013). Focus was on using oral presentation for learning and assessment. In addition, most of those studies were done in English-as-a-Second-Language (ESL) contexts (Zappa-Hollman, 2007); very few were done in English as a Foreign Language (EFL) or in the English language 
classroom (Abu El Enein, 2011). Not only that, but most of those studies were done on graduate students from other disciplines, such as engineering, medicine, and business (Preub, Schoofs, Schlotz \& Wolf, 2010; Radzuan \& Kaur, 2011; Alwi \& Sidhu, 2013). Hence, research providing more detailed insight into undergraduate classroom oral presentations in EFL higher-education settings as a form of assessment is scarce (Joughin, 2007; Zappa-Hollman, 2007; Alwi \& Sidhu, 2013). Morita (2000) sees oral activities such as presentations challenging and complex in terms of interaction and mental processes and suggests more research to be conducted. Ercan, Irgil, Sigirli, Ozen \& Kan (2008) recommend investigating students' perceptions in order to access what is going on in their minds.

Thus, to investigate female EFL college students' perceptions of the difficulties in classroom oral presentation as a form of assessment will help us understand better and cater more to students' needs as well as recognize and acknowledge their weaknesses. The results of this study will hopefully complement existing research about challenges facing non-native speakers in higher education. Thus, the aim is to elucidate the challenges students experience during their oral presentations that have negative effects on their performance. According to Zappa-Hollman (2007), linguistic problems were seen as the most challenging during oral presentations, and Dornyei and Kormos (2000) point out that the challenge facing students results from trying to convey their thoughts and at the same time understand what is said despite limited language ability. This results in an emotional condition that is different when communicating in the native tongue. Thus, the present study intends to provide more insight into the challenges specifically facing English major, undergraduate college students during their classroom oral presentations, not only in an EFL context, but also in an Arabic context in which socio-cultural differences have an impact on students' perceptions.

\section{Assessment at the College of Basic Education (CBE)}

The Public Authority for Applied Education and Training (PAAET) was founded in 1985 in Kuwait City, Kuwait. Four colleges were under the auspices of the PAAET, namely, the College of Basic Education (CBE), the College of Business Studies (CBS), the College of Technological Studies (CTS), and the College of Health Sciences (CHS). Only high school graduates were accepted at these colleges.

In the academic year 2001/2002, the English Department at the CBE introduced a new program. This program lasts four years, after which students are awarded the degree of B.Ed. in English. The program aims to provide the Ministry of Education with competent female English-language school teachers. Students must complete 130 Credit Hours. The English major alone is 60 credit hours, of which 12 credits are attributed to the Basic Language Skills, 12 credits for Literature, 21 credits for Theoretical and Applied Linguistics, and 15 credits for English as a Foreign/Second Language. In addition, students must take two French courses in partial fulfillment of the General Education Requirements. Admission to the department necessitates passing an Admission Test designed by the department and includes an oral interview.

Assessment at the CBE varies. Instructors have the freedom to choose their own mode of assessment. However, the general requirement is 100 points to be distributed as follows: 50 points to be assigned for the final written exam and 50 points for course work. Two quizzes are required at minimum in addition to one mid-term written exam. The rest of the points are usually assigned to oral presentations, projects, and other assignments.

\section{Statement of the Problem}

A major challenge of Foreign Language (FL) instruction is to develop learners' oral communication skills, because the primary goal of language teaching is the production of qualified teachers of the target language. Unfortunately, university and college Arab students in general face communication problems, specifically oral issues (Rababah, 2005). Toumi (2011), the Bureau Chief at Gulf News, reported the Kuwaiti Education Minister saying that Kuwait's education system should focus on developing communication skills and boosting students in FL. He said that the education system should abandon the traditional way of teaching, in which students memorize and reproduce in exams: "We aspire to have a generation that is well aware of the importance of communication and the significance of the culture of dialogue" (Toumi, 2011). Similarly, in the Arab Times Sadeqhi (2014) argues that although there are talks about developing the education system, in practice Kuwait is still very behind. Traditional methods of teaching that lack learner-centered components and e-learning are still in use. Sadeqhi (2014) believes that most students are not ready for critical thinking and teachers are not yet ready to be creative. She concludes that the low level of the current Kuwaiti students is the responsibility of the Ministry of Education.

Added to that, English is taught as a compulsory subject for 12 years in general education. The only way to learn English is in the classroom, in which all language teachers are native speakers of Arabic. From our experiences as teachers, learners spend most of their time doing grammar and vocabulary exercises instead of practicing oral presentations. Promoting oral communication skills, which requires students to practice in real-life situations, is 
completely overlooked. In addition, students have little chance to apply what they have learned in class to the outside world. As a result, many high school graduates are unable to express themselves or engage in real conversation. They are working to produce error-free language structures, yet many of them continue to make errors in their productive skills (i.e., speaking and writing). Thus, a large number of high school students cannot meet the requirements of undergraduate colleges that urge them to use productive skills and to be communicatively competent. As a result, one of the skills that college students find the most challenging is oral presentation skills.

\section{Literature Review}

Researchers and educationalists have been preoccupied lately trying to emphasize the role of oral presentation in students' academic careers, especially at undergraduate and postgraduate levels (Liow, 2008; Wolfe, 2008; Munby, 2011). The majority of those studies were devoted to ways of conducting proper oral presentations (e.g., Abu El Enein, 2011). Some studies, on the other hand, listed the benefits of oral presentation, such as helping instructors cater to students' learning styles, practicing speaking, providing students with a deep understanding of the presentation topic, and providing independent, critical learning to facilitate cooperative learning and to introduce students to technology (Al-Issa \& Al-Qubtan, 2010; Munby, 2011).

Yet, other studies were concerned with listing the difficulties that students usually face in oral presentation, such as feeling nervous (Chuang, 2009; Abu El Enein, 2011 Alwi \& Sidhu, 2013). One of the main difficulties reported facing students in oral presentation was anxiety or fear of speaking. Research has consistently revealed that anxiety can impede EFL students' production and achievement (Al-Nouh; Abdul-Kareem \& Taqi, 2014). In addition, some studies investigated the reasons behind students' anxiety, such as lack of vocabulary (Subasi, 2010; Mazdayasna, 2012), while others proposed ways to overcome these difficulties, such as choosing a familiar topic and practicing a lot (e.g. Zappa-Hollman, 2007).

In addition, a growing number of studies aimed to investigate the reasons behind students' low performance in oral presentations (Turner; Roberts; Heal \& Wright, 2012; Akindele \& Trennepohl, 2014). These can be grouped under three categories. First, personal traits such as shyness, fear of facing an audience, self-confidence, and physical appearance. Elliott and Chong (2004) found that students' personal traits were the reason behind their feelings of anxiety during oral presentation. Second, the audience and the instructor were believed to be main reasons for students' unwillingness to present (e.g., negative evaluations, hard questions, humiliating feedback, etc.) (Wolfe, 2008). Finally, lack of presentation skills were seen to play a crucial role in students' feelings of anxiety (e.g., researching, planning, organizing, practicing, and presenting) (Leichsenring, 2010).

As seen above, although there are different factors that affect students' oral presentation, most of them stem from anxiety of speaking. In the next section, studies reporting the effect of the above factors on students' oral presentation are discussed.

\subsection{Personal Traits}

Studies of oral assessment have occasionally noted the potentially inhibiting role of anxiety in affecting students' ability to perform (Joughin, 2007). To investigate the effect of personal traits on performance and specifically, to find out how students' status and familiarity with English language affect anxiety level, Elliot and Chong (2004) solicited the opinions of first-year university students in Australia and found that one third of the sample had a high or very high level of presentation anxiety. Two thirds of the students believed that their level of anxiety affected their performance. Interestingly, it was found that the level of anxiety was higher for international students.

Not only undergraduate but also graduate students were reported being anxious during oral presentations. For example, Zappa-Hollman (2007) wanted to explore the discourse socialization of non-native graduate students in Canada while engaging in an academic oral presentation. It was found that students were shy and afraid to present in front of a large audience. Students feared oral presentation as it involved a number of skills.

Similarly, Chen (2009) wanted to investigate Taiwanese graduate students' anxiety levels as well as identify the sources of anxiety in oral presentation. Results showed students were moderately anxious. Most of the difficulties reported were self-perceived personality issues.

More research on the sources of anxiety was conducted by Chuang (2010), who investigated the sources of anxiety of speaking English and anxiety-driven situations. Results showed undergraduate students felt anxious even if prepared in advance, felt their peers spoke better English than they did, felt uncomfortable and shy when they had to speak in front of others, and were afraid that the teacher would pay attention to their English mistakes.

Likewise, anxiety might stem from lack of self-confidence, which affects students' overall performance. For example, Al-Hebaish (2012) wanted to investigate the correlation between the self-confidence of Saudi undergraduate female 
English majors and their academic achievement in the oral presentation course. Findings showed that there is a positive, significant correlation between self-confidence and achievement in oral presentation tests. Self-confident learners were willing to speak out and take the risks, while learners with low self-confidence try less.

\subsection{Presentation Skills}

Lack of presentation skills was believed to be the second most important factor that causes difficulty in oral presentation. In a related study to explore the factors that influence students' oral presentations, Leichsenring (2010) reported that EFL undergraduate Japanese students want to speak better English and to lower their language anxiety. They worried about making mistakes, which resulted in their memorization of content. They also believed that presenting in English was difficult and reported problems with planning and preparing a presentation.

Similarly, inadequate presentation skills result in poor performance. For example, Chuang (2011) tried to find out college non-English-major students' perceptions of oral language activities in which oral presentations played a major role. Students reported a preference for reading from notes, a lack of audience or teacher feedback to guide them in their presentations, the inability to choose their own topics, poor vocabulary, and inadequate presentation skills.

To further understand students' competence in oral presentation, there is a need to compare their competence with their performance. For example, Alwi and Sidhu (2013) wanted to compare Malaysian faculty-degree students' evaluations of their levels of competence with their actual performance in oral presentations. Findings showed students perceived themselves better than how they were rated by the examination board. However, actual performances showed they had weaknesses in language and delivery skills.

\subsection{Audience \& Instructor}

Likewise, fear of facing the audience and the instructor was reported by most studies as the worst fear of all in oral presentations. And because learners are the best conveying their beliefs and feelings, researchers were particularly interested in finding out about learners' attitudes and perceptions towards oral presentations. To explore college students' attitudes towards oral presentations, Wolfe (2008) found students reporting audience reactions as an unpleasant experience in oral presentations as well as group presentations in which group members do not share the work equally. Wolfe ultimately concluded that fear of public speaking was rated as the worst fear for many students.

Fear of public speaking might be the result of the culture of learning. Indeed, Lee (2009) reported graduate students having passive personalities as a result of a Korean learning culture that privileges silence and passivity. Difficulties reported were the inability to contact the professor's eyes and their classmates' reactions, which caused them to panic and forget their material.

Furthermore, and in a more recent study, Radzuan and Kaur (2011) found that undergraduate students' primary source of anxiety was the harsh and frightening evaluation committee. Students were seen to fear the committee's difficult questions, criticism, and interruptions of their presentations.

Finally, in a more related study that reports most of the previous difficulties, Abu Al-Enein (2011) wanted to identify the main difficulties encountering university English majors during oral presentations from students' and instructors' perspectives. Findings revealed a number of difficulties, such as student lack of motivation to give presentations, lack of confidence in their abilities, anxiety and fear, lack of eye contact with the audience, focusing on accuracy more than fluency, incorrect pronunciation, lack of proper vocabulary, weak speaking skills, inability to use technology, poor time management, and interlingual mistakes while presenting.

All in all, most of the studies in the literature have been conducted in English as a Second Language (ESL) contexts, which have socio-cultural differences from EFL contexts. Subasi (2010), for example, argues that differences in foreign language situations and reasons for foreign-language classroom anxiety requires more research with the understanding that anxiety-provoking factors may differ from context to context. In addition, the literature on undergraduate English-major students' needs in classroom oral presentations as a form of assessment is limited (Alwi \& Sidhu, 2013). Likewise, a large part of the literature was interested in thesis oral presentations rather than undergraduate presentations as a form of assessment. Also, most of the studies above used either a small sample or a single method to collect data, which limits the applicability of the results to the general population.

Discussing the topic of oral presentations is of great importance to students because it helps increase their understanding of the subject and helps them acquire critical and analytic skills that are required in higher education and future careers. Nowadays, it is a requirement in higher education that students come equipped with advanced written and oral skills (Tuan \& Neomy, 2007). Knowing the difficulties that students face during oral presentation will help instructors understand students' needs and provide them with better opportunities to improve. Emden and 
Becker (2004) state that teaching students to present in front of an audience is one of the most useful skills students can acquire in higher education. Furthermore, soliciting students' perceptions is crucial because they are most knowledgeable about their subjective responses, and the information they provide is invaluable. Adding to this is the fact that oral presentation is gaining more importance as an oral activity used in different disciplines and as a form of assessment.

Driven by concerns about students' academic success, the present study aims to solicit female EFL undergraduate college students' perceptions of the difficulties in oral presentations as a form of assessment. It intends to look at the factors that affect students' oral presentation from three perspectives: personal traits, oral presentation skills, audience and instructor. To this end, the following research questions were addressed:

1. What are the overall EFL college students' perceptions of the difficulties in oral presentations?

2. Do EFL college students' perceptions differ according to age?

3. Do EFL college students' perceptions differ according to years at college?

4. Do EFL college students' perceptions differ according to nationality?

5. Do EFL college students' perceptions differ according to GPA?

6. Which one of the following factors-" "personal traits," "oral presentation skills," "audience," or "instructor"-has more impact on EFL college students' oral presentations from the students' perspectives? Does it match with the instructors' perspectives?

7. What are the instructors' opinions of the main difficulties that English-major students face during oral presentations?

\section{Method}

A mixed-method approach using quantitative and qualitative data was employed.

\subsection{Participants}

The participants of the study fell into two groups. The first group of participants consisted of 10 instructors, males and females of different ages, experience, and nationality teaching in the English Department at the CBE. The second group consisted of 500 female EFL undergraduate students studying at the CBE for the academic year 2014-2015. Students enrolled in a four-year program for the preparation of EFL teachers for young learners. Of the 500 students, 494 handed in completed questionnaires. Their age range was between 17-20 (45.3\%) and 21-43 $(54.7 \%)$ with a mean age of 22.2 years. Table 1 displays sample information.

Table 1. Distribution of Sample

\begin{tabular}{|c|c|c|}
\hline Independent Variables & No. & $\%$ \\
\hline \multicolumn{3}{|l|}{ Grade Level * } \\
\hline First Grade & 50 & 10.1 \\
\hline Second grade & 147 & 29.8 \\
\hline Third grade & 187 & 37.9 \\
\hline Fourth grade & 109 & 22.1 \\
\hline Total & 493 & $100 \%$ \\
\hline \multicolumn{3}{|l|}{ Age } \\
\hline 20 and less & 224 & 45.3 \\
\hline 21 and more & 270 & 54.7 \\
\hline Total & 494 & $100 \%$ \\
\hline \multicolumn{3}{|l|}{ Nationality } \\
\hline Kuwaiti & 405 & 82.0 \\
\hline non-Kuwaiti & 89 & 18.0 \\
\hline Total & 494 & $100 \%$ \\
\hline \multicolumn{3}{|l|}{ General G.P.A * } \\
\hline $3.67-4.00$ & 69 & 14.2 \\
\hline $3.50-2.67$ & 215 & 44.3 \\
\hline $2.50-1.67$ & 168 & 34.6 \\
\hline 1.50 and less & 33 & 6.8 \\
\hline Total & 434 & $100 \%$ \\
\hline
\end{tabular}

* Variables were participants were less than 494 are those that participants did not answer. 


\subsection{Instrument}

\subsubsection{Students' Questionnaire}

A 40-item questionnaire with a five-point Likert-type Scale (1=never, 2=rarely, 3=sometimes, 4=often, and $5=$ always) was developed by the researcher after an extensive review of the literature on oral presentations (Morita, 2000; Elliott \& Chong, 2004; Wolfe, 2008; Chuang, 2010; Vitasari, Abdul Wahab; Othman \& Awang, 2010). It consisted of four sections: the first section described the demographic information of the sample, the second section consisted of 14 items and aimed to depict the participants' personal traits, the third section was set to find out about participants' presentation skills and consisted of 15 items, and the last section addressed the effect of audience and instructor on participants' oral presentations and consisted of 9 items.

Two open-ended questions were asked at the end of the questionnaire to elicit extra information from participants. Question 39 asked participants to describe an unpleasant experience they had during an oral presentation and question 40 asked them to rearrange the factors that were believed to cause some of the difficulties in oral presentation, from the most $(\mathrm{N}=1)$ to the least important $(\mathrm{N}=4)$ (research question 6). They were further given a space for adding other factors.

\subsubsection{Instructors' Interview}

A structured interview consisting of 5 questions was set to elicit the difficulties students face during oral presentation as a form of assessment from the instructors' perspective in order to compare them with students' responses from the questionnaire. The interview asked instructors to describe a successful oral presentation from their point of view and what were the most important criteria for assessing oral presentations. In particular, instructors were asked about the difficulties students encounter during oral presentations and how a teacher can be a source of such difficulty. Teachers were further asked to rearrange a set of difficulties students are believed to face during oral presentation from the most $(\mathrm{N}=1)$ to the least important $(\mathrm{N}=4)$. In the end, instructors were asked about their recommendations for improving oral presentation assessment in the department.

\subsection{Procedure}

\subsubsection{Students' Questionnaire}

Before administering the questionnaire, the researcher managed to elicit a group of students' feedback about the difficulties they face during oral presentations. The questionnaire was then written based on students' comments and the literature review. For ease of comprehension and to allow students to express themselves freely, the questionnaire was written in the students' first language. Next it was revised by two experts in the field for suitability of content and language. Afterwards, a pilot study was conducted on 30 female EFL undergraduate students (not included in the main study) prior to the actual implementation of the questionnaire to verify the reliability and validity of the instrument. As a result, two items were deleted as proposed by the reviewers to ensure research quality. A Cronbach Alpha of 0.90 was calculated indicating a high reliability of the scale. Consequently, the actual implementation of the questionnaire took place during the first term of the academic year 2014-2015 at the CBE.

\subsubsection{Instructors' Interview}

All interviews were conducted by the researcher. Instructors' consents for the interview were taken verbally. Instructors were interviewed at specified times according to their convenience and availability. All interviews were conducted in English and were tape-recorded, and the researcher managed to take notes simultaneously. Each interview took between 10-15 minutes.

\section{Data Analysis}

\subsection{Students' Questionnaire}

Descriptive statistics, including frequencies, percentages, means, and standard deviations, were employed to measure students' perceptions of the difficulties they face during oral presentations from three perspectives: personal traits, oral presentation skills, audience and instructor. Other tests included a t-test to compare differences between participants in age and nationality and a one-way ANOVA test to compare grade levels and general GPAs.

For ease of statistical analysis, participants' perceptions were grouped under three main headings: low, medium, and high:

- $\quad 1.00-2.33=$ low mean value

- $\quad 2.34-3.66=$ medium mean value 
- $\quad 3.67-5.00=$ high mean value

The open-ended questions (39 and 40) were analyzed manually. The researcher looked for common themes in the data and then grouped them under main headings.

\subsection{Instructors' Interview}

Tapes were transcribed and the data were analyzed manually. The researcher examined the data looking for repeated themes, grouped those together, and then chose appropriate headings for the categorized data. A colleague who specialized in the field reexamined the data for reliability and validity purposes.

\section{Results \& Discussion}

\subsection{Students' Questionnaire}

As indicated above, the first research question aimed to find out EFL students' overall perceptions of the difficulties in oral presentation. Generally speaking, the findings indicate a medium level $(\mathrm{M}=3.10)$ as shown in Table (2) below:

Table 2. General Means and Standard Deviations for College Students' Perceptions of the difficulties of Oral Presentation

\begin{tabular}{cccc}
\hline Factors & M & SD & Rank \\
\hline Personal Traits & 3.06 & .79 & Medium \\
Oral Presentation Skills & 2.93 & .80 & Medium \\
Audience \& Instructor & 3.41 & .84 & Medium \\
Total & 3.10 & .73 & Medium
\end{tabular}

The means and standard deviations were established for students' perceptions of oral presentation according to Table 2.

Results suggest students sometimes face difficulties during oral presentation. This is inconsistent with Chuang's study (2011) in which students perceived oral presentations to be poorly delivered, assessed, and received. The inconsistency can be explained by the fact that the Ministry of Education started lately to emphasize oral-presentation assessment in elementary and intermediate schools. Twice in a course pupils were told to prepare a topic chosen by the teacher of no more than five lines and either read or memorize and recite it. However, this assessment is not done regularly, pupils do not get proper feedback from the teacher, and memorization is encouraged. Hence, students are liable to face some difficulties that will be discussed below.

\subsubsection{Personal Traits}

Table 3 below reflects students' perceptions of the difficulties in oral presentation assessment in relation to personal traits. Although the mean reflects a medium level $(\mathrm{M}=3.24)$ as shown in statement 1 , a large number of students $(39.9 \%)$ said that they "sometimes" dislike oral presentations, followed by those who said "always" (22.5\%) and those who said "often" (14.2\%). This is consistent with Zappa-Hollman's study (2007) in which students reported oral presentation as "daunting," involving a number of skills.

Similarly, statement 3 showed nearly half the students (42.0\%) reporting that they "always" feel anxious before an oral presentation exam $(M=3.85)$ followed by $20.8 \%$ who said they "often" do. This is also supported by most studies reporting students feeling anxious before an oral presentation (Vitasari et al., 2010; Abu El-Enein, 2011; Radzuan \& Kaur, 2011). In particular, it conforms to Kitano's (2001, in Chuang, 2010) findings that students' anxiety levels were positively correlated with their fear of negative evaluation. It seems that students see their apprehension about exams as a situation-specific anxiety that has nothing to do with oral presentation itself (Al-Nouh et al., 2014).

Likewise, a large number of students reported that they "sometimes" get embarrassed and feel worried during presentations, although they never skip an oral presentation class. This is not in line with Alwi and Sidhu's study (2013) reporting students experiencing high anxiety, embarrassment, and lack of confidence during oral presentation. 
Table 3. Means and Standard Deviations for EFL college students' perceptions of the difficulties in oral presentation according to personal traits

\begin{tabular}{llccc}
\hline No. & \multicolumn{1}{c}{ Statement } & M & SD & Rank \\
\hline 1 & I don't like the idea of oral presentations. & 3.24 & 1.25 & Medium \\
2 & I like to do an oral presentation with a group. & 3.40 & 1.49 & Medium \\
3 & I feel very anxious before an oral presentation exam. & 3.85 & 1.20 & High \\
4 & I find an oral presentation exam difficult because I have low & 2.83 & 1.33 & Medium \\
& self-confidence. & & & \\
5 & I feel embarrassed when I do an oral presentation in English. & 2.75 & 1.37 & Medium \\
6 & I'm worried because of my low English-speaking ability. & 2.70 & 1.33 & Medium \\
7 & On presentation day I skip class. & 1.57 & 1.14 & Low \\
\hline
\end{tabular}

The means and standard deviations were established for EFL college students' perceptions of oral presentation according to Table 3 .

Indeed, a large number of students (41.9\%) reported "always" bringing their written notes with them during their oral presentation, even if well-prepared. It seems that notes make students feel more secure and reduce their anxiety. Similarly, Chuang (2011) noted that students in his study reported the need for note cards; otherwise, the presentation was impossible. Chuang (2009) believed that anxiety affects cognitive abilities and thus students learned less and were unable to display what they had learned. Nevertheless, he recommended presentations without notes to be more effective for improving students' oral ability. Thus, it behooves instructors to help their students minimize the use of notes during presentations.

This finding is further confirmed in statement 9, for which many students (39.2\%) reported "always" feeling worried, even if prepared. Oral presentations during which students stand up and talk in front of people is considered an anxiety-provoking situation. Joughin (2007) believes that oral presentation is more demanding than writing; it is more personal and involves more pressure on the presenter. Likewise, Zappa-Hollman (2007) found that oral presentation was seen by students as daunting because it included the mastery of a combination of skills, talking, and leading an open discussion. This is also confirmed by most of the studies discussed earlier.

Statements 10, 13, and 14 show a "medium" mean response, even though more than half the students (55.7\%) said "always" and "often" to statement 14, indicating apprehension of oral presentations. A possible explanation could be that giving an oral presentation depends on many factors, one of which is the psychological or personality factor. Other factors could be the instructors' use of different criteria for evaluation. Instructors sometimes recommended during the interview using guidelines that all instructors can follow.

Table 4. Means and Standard Deviations for EFL college students' perceptions of the difficulties in oral presentation according to personal traits

\begin{tabular}{llccc}
\hline No. & \multicolumn{1}{c}{ Statement } & M & SD & Rank \\
\hline 8 & $\begin{array}{l}\text { I bring notes with me during my oral presentation even if I am } \\
\text { well prepared. }\end{array}$ & 3.85 & 1.21 & High \\
9 & I feel worried even if I have prepared well beforehand. & 3.79 & 1.22 & High \\
10 & When I start my oral presentation, I forget everything I wanted & 3.20 & 1.23 & Medium \\
& to say. & 3.07 & 1.25 & Medium \\
11 & I feel my peers speak English better than me. & 1.92 & 1.34 & Low \\
12 & I hate oral presentations because of a past negative experience. & 3.32 & 1.40 & Medium \\
13 & I feel shy during oral presentations. & 3.60 & 1.36 & Medium \\
14 & I'm afraid of failure in oral presentations. & & &
\end{tabular}

The means and standard deviations were established for EFL college students' perceptions of oral presentation according to Table 4 . 


\subsubsection{Oral Presentation Skills}

The second main factor suggested to have an impact on participants' oral presentation is presentation skills. As seen from Table 5 below, statement 15 shows a large number of students $(66.9 \%)$ feel the need to read from notes during oral presentations. This is in line with previous research in which participants were found reading from notes and not making eye contact (Chuang, 2011). Interestingly, Zappa-Hollman (2007) found that non-native speakers of English were used to reading aloud from their notes during their oral presentation. This also supports the answers to statement 8, for which most participants reported "always" bringing their written notes, even if well-prepared.

Other difficulties participants reported were keeping within the time limit of the oral presentation, and a number of them (23.7\%) reported "sometimes" having difficulty with this. As discussed above, responses vary depending on the topic and the instructor. This was further reported as a difficulty by Abu El Enein (2011) in his study, in which significant differences were found concerning time management among participants.

A very interesting finding is for statement 17 , for which almost half the participants $(44.3 \%)$ reported the need to see a peer's presentation before doing their own. This might suggest unfamiliarity with oral presentation and the need for modeling this activity. Zappa-Hollman (2007) refers to modeling as a strategy used in oral presentations during which some students prefer to witness a peer presentation before doing their own.

When it comes to using technology, however, most participants (60.1\%) strongly believe that they are knowledgeable. Indeed, given the first author's experience as an instructor at the CBE, students have good technological skills.

Students $(58.2 \%)$ further believe that they know how to do an oral presentation (statement 19). When it comes to self-evaluation, it seems that students have great confidence in themselves and in their abilities. This finding resonates with Alwi and Sidhu's (2013) findings in which students rated themselves better than how the examination panel rated them. Indeed, one of the instructors in the interview reported students having great confidence in themselves even when they lack presentation skills.

Linguistic difficulties such as lack of fluency, grammar, and vocabulary knowledge (statements 20, 21), were further emphasized in the results. This reflects a culture of learning that emphasizes rote memorization of grammar rules and vocabulary lists and lacks opportunities for interaction. Munby (2011) explains that it is the result of grammar translation tests used in English secondary education in Asian countries.

Table 5. Means and Standard Deviations for EFL college students' perceptions of the difficulties in oral presentation according to presentation skills

\begin{tabular}{llccc}
\hline No. & \multicolumn{1}{c}{ Statement } & M & SD & Rank \\
\hline 15 & I need to read from my notes during oral presentations. & 3.10 & 1.32 & Medium \\
16 & $\begin{array}{l}\text { I find it difficult to abide by the time constraints of the } \\
\text { presentation. }\end{array}$ & 2.48 & 1.32 & Medium \\
17 & I prefer to see someone's presentation before starting my own. & 3.86 & 1.27 & High \\
18 & I don't know how to use technology in my oral presentation. & 2.30 & 1.34 & Low \\
19 & Not knowing how to do an oral presentation is the reason behind & 2.33 & 1.35 & Low \\
& my low performance. & & & \\
20 & I care about grammar more than fluency in oral presentation. & 2.92 & 1.22 & Medium \\
21 & $\begin{array}{l}\text { During oral presentation, I think in Arabic then translate it into } \\
\text { English. }\end{array}$ & 2.77 & 1.47 & Medium
\end{tabular}

The means and standard deviations were established for EFL college students' perceptions of oral presentation according to Table 5 .

Additionally, more than half the students (57.4\%) believe that the conversation course is not enough to improve their speaking skill (statement 22 ) and $44.4 \%$ of them believe that shortage of oral-skills courses is the reason behind their low performance. Unfortunately, there are no courses tailored for the development of oral presentation skills. Students acquire presentation skills by performing them in other courses.

Other difficulties reported by students were shortage of vocabulary knowledge (statement 24), which is supported by the answers to statement 21, for which students translate from Arabic to English, a task that eventually affects their 
oral fluency (statement 25). This is further supported by statement 20 responses, for which students reported focusing on grammar at the expense of fluency.

When it came to students' preferences for assessment (statement 26), more than half the students (52.8\%) preferred written exams. Higher education in Kuwait places great emphasis on written exams at the expense of oral assessment. This is similar to Chuang's (2010) findings, in which $46.3 \%$ of students said that taking a written test would be less daunting than an oral one. It is believed that oral presentation is more or even equally demanding as the written assignment (Joughin, 2007).

But when asked if they prefer memorization to understanding the topic, most students responded with "never" and "rarely." However, from the first author's experience as an instructor, many students memorize without understanding the topic. When it comes to preference, it seems that students choose what they think is the best answer and not necessarily what they actually do. Other difficulties reported were topic difficulty and organization of ideas, findings also reported in previous studies.

Table 6. Means and Standard Deviations for EFL college students' perceptions of the difficulties in oral presentation according to presentation skills

\begin{tabular}{llccc}
\hline No. & \multicolumn{1}{c}{ Statement } & M & SD & Rank \\
\hline 22 & $\begin{array}{l}\text { The conversation course is not enough to improve my speaking } \\
\text { skill. }\end{array}$ & 3.66 & 1.31 & Medium \\
23 & $\begin{array}{l}\text { Not having courses in oral presentation is the reason behind my } \\
\text { low performance. }\end{array}$ & 3.24 & 1.42 & Medium \\
24 & $\begin{array}{l}\text { I find it hard to find the suitable word to express my meaning. } \\
25\end{array} \quad \begin{array}{l}\text { I have a problem with oral fluency and pronunciation during } \\
\text { oral presentation. }\end{array}$ & 2.34 & 1.18 & Medium \\
26 & $\begin{array}{l}\text { I prefer to be assessed by written exams rather than oral } \\
\text { presentations. }\end{array}$ & 3.50 & 1.42 & Medium \\
27 & $\begin{array}{l}\text { I prefer to memorize the topic of the oral presentation rather } \\
\text { than understand it. }\end{array}$ & 2.11 & 1.36 & Low \\
28 & $\begin{array}{l}\text { The difficulty of the topic is the reason behind my low } \\
\text { performance in oral presentation. }\end{array}$ & 2.68 & 1.26 & Medium \\
29 & $\begin{array}{l}\text { I find it difficult to organize my ideas logically during oral } \\
\text { presentation. }\end{array}$ & 2.84 & 1.29 & Medium
\end{tabular}

The means and standard deviations were established for EFL college students' perceptions of oral presentation according to Table 6 .

\subsubsection{Audience / Instructor}

To support the fact that students experience some difficulties in oral presentations, most students (55.1\%) reported feeling afraid to present in front of an audience (statement 30). These findings echo with Alwi and Sidhu's (2013) reporting that students barely make eye contact with the audience. Similarly, Joughin (2007) observed students feeling anxious when speaking English in front of their peers. Also, a large number of students $(62.1 \%)$ reported that when late students enter the classroom or talk to each other, it confuses them during oral presentation.

As to instructor's presence, $56.1 \%$ of the students said that the instructor's interrupting of their presentations with questions and criticism affects their performance (statement 34). This is consistent with Radzuan and Kaur's study (2011) in which students reported the evaluation panel's attacking them with difficult questions and criticism and interrupting them to make comments. In addition, many students $(53.6 \%)$ felt anxious when their instructors were attending to their language and others said they "always" try to avoid looking at the instructor's eyes during oral presentation. What is more, a high percentage of students (60.3) $(\mathrm{M}=3.81)$ reported "always" and "often" the fear of receiving unfair grades for their presentations. This might be because of the fact that every instructor has his/her own criteria, and most of the time students were not informed of the criteria for evaluation. Irvine (2012) confirms that oral presentations are subjective in that different teachers look for different things. These results were supported by Fang-peng and Dong's study (2010) in which fear of negative evaluation was found to be a source of anxiety in the EFL classroom. 
Table 7. Means and Standard Deviations for EFL college students' perceptions of the difficulties in oral presentation according to audience \& instructor

\begin{tabular}{llccc}
\hline No. & \multicolumn{1}{c}{ Statement } & M & SD & Rank \\
\hline 30 & $\begin{array}{l}\text { I feel frightened when a lot of people are watching me. } \\
31\end{array}$ & 3.61 & 1.31 & Medium \\
& $\begin{array}{l}\text { Students' reactions affect my performance in the oral } \\
\text { presentation. }\end{array}$ & 3.30 & 1.25 & Medium \\
32 & $\begin{array}{l}\text { I worry that students will laugh at me when I speak English. } \\
33\end{array}$ & 2.68 & 1.40 & Medium \\
& $\begin{array}{l}\text { When late students enter class or talk to each other during oral } \\
\text { presentation, I lose my ideas. }\end{array}$ & 3.81 & 1.26 & High \\
34 & $\begin{array}{l}\text { The instructor's interruption with questions or criticism affects } \\
\text { my performance. }\end{array}$ & 3.65 & 1.25 & Medium \\
35 & $\begin{array}{l}\text { I feel anxious because the instructor is watching my language. } \\
36\end{array}$ & 3.57 & 1.30 & Medium \\
37 & $\begin{array}{l}\text { I try to avoid the instructor's eyes during oral presentation. } \\
\text { presentation. }\end{array}$ & 3.29 & 1.48 & Medium \\
38 & $\begin{array}{l}\text { I don't get useful feedback from the instructor after the oral } \\
\text { presentation. }\end{array}$ & 3.81 & 1.24 & High \\
\hline
\end{tabular}

The means and standard deviations were established for EFL college students' perceptions of oral presentation according to Table 7 .

Concerning research question two, which aimed to find out whether there were differences between EFL college students' perceptions of the difficulties in oral presentation based on their age, it was found that age did not show a significant effect on the three factors. This can be explained by the fact that the participants had a mean age of 22.2 years. Most of them were between 19 and 22 years which makes it difficult to find significant differences because the ages were not far apart.

As to research question three about whether there were significant differences between EFL college students' perceptions of the difficulties in oral presentation according to years at college, results did not show any significance. Similarly, no differences were found between senior and junior students in Abu El Enein's (2011) study above.

It was found that "years at college" did not make individual differences among students. After discussing it with students, it was realized that second-year students were allowed to take more courses (i.e., credit hours) than do third-year students. Thus, there might be differences based on the number of credit hours students take rather than years at college. In a future study, it is recommended that credit hours be used as an independent variable to establish possible significant differences.

Regarding question four about whether EFL college students' perceptions of the difficulties in oral presentation differ according to nationality, table 8 illustrates the results.

Table 8. T-test of students' perceptions of the difficulties in oral presentation in relation to the three factors according to nationality

\begin{tabular}{|c|c|c|c|c|c|c|c|}
\hline No & Factors & Nationality & $\mathrm{N}$ & $\mathrm{M}$ & SD & $\mathrm{T}$ & Sig \\
\hline \multirow[b]{2}{*}{1} & \multirow[b]{2}{*}{ Personal Traits } & Kuwaiti & 405 & 3.11 & .78 & \multirow[b]{2}{*}{2.97} & \multirow[b]{2}{*}{0.003} \\
\hline & & $\begin{array}{c}\text { Non- } \\
\text { Kuwaiti }\end{array}$ & 89 & 2.84 & .80 & & \\
\hline \multirow[b]{2}{*}{2} & \multirow[b]{2}{*}{ Presentation Skills } & Kuwaiti & 405 & 2.97 & .84 & \multirow[b]{2}{*}{2.35} & \multirow[b]{2}{*}{0.019} \\
\hline & & $\begin{array}{l}\text { Non- } \\
\text { Kuwaiti }\end{array}$ & 89 & 2.75 & .79 & & \\
\hline \multirow[b]{2}{*}{3} & \multirow[b]{2}{*}{ Audience \& Instructor } & Kuwaiti & 405 & 3.46 & .85 & \multirow[b]{2}{*}{2.38} & \multirow[b]{2}{*}{0.014} \\
\hline & & $\begin{array}{c}\text { Non- } \\
\text { Kuwaiti }\end{array}$ & 89 & 3.22 & .79 & & \\
\hline
\end{tabular}

The t-test of students' perceptions of the three factors according to nationality are shown in Table 8 
Significant differences were found between Kuwaiti and non-Kuwaiti students in all three factors. In fact, Kuwaiti students seemed to experience the most difficulties with oral presentations. As mentioned above, this could be a result of the traditional teacher-centered approaches in secondary school, in which the focus is on teaching grammar and memorizing vocabulary instead of language use. This finding is substantiated by Tahira (2011), who said, "In Kuwait, rote methods are often used to memorize grammar rules, answers to reading comprehension questions and vocabulary words" (p. 8). Another explanation might be the lack of oral presentation courses tailored to equip students with the necessary skills required for academic presentations. Added to that is the shortage of oral-skill courses offered by colleges. As for non-Kuwaitis, most come from private or bilingual schools and are already equipped with the necessary skills for oral presentations. Also, private schools use alternate communication methods through which students are encouraged to speak. Other reasons for the greater preparation of private-school students could be that their parents, who are usually doctors, engineers, and other professionals, push them more strongly to excel, along with their own desire to be admitted at a college.

As to question 5, which investigates whether EFL college students' perceptions of the difficulties in oral presentation differ according to their GPAs, table 9 presents the results.

Table 9. One-Way ANOVA Test for Students' Perceptions of the difficulties in oral presentation according to GPA

\begin{tabular}{|c|c|c|c|c|c|c|c|}
\hline No & Factors & GPA & $\mathrm{N}$ & $\mathrm{M}$ & SD & $\bar{F}$ & Sig. \\
\hline \multirow{4}{*}{1.} & \multirow{4}{*}{ Personal Traits } & $3.67-4.00$ & 69 & 2.56 & .90 & \multirow{4}{*}{13.95} & \multirow{4}{*}{.000} \\
\hline & & $3.50-2.67$ & 215 & 3.07 & .77 & & \\
\hline & & $2.50-1.67$ & 168 & 3.21 & .72 & & \\
\hline & & $1.50 \&$ less & 33 & 3.40 & .63 & & \\
\hline \multirow{4}{*}{2.} & \multirow{4}{*}{ Presentation Skills } & $3.67-4.00$ & 69 & 2.53 & .85 & \multirow{4}{*}{10.45} & \multirow{4}{*}{.000} \\
\hline & & $3.50-2.67$ & 215 & 2.90 & .85 & & \\
\hline & & $2.50-1.67$ & 168 & 3.08 & .74 & & \\
\hline & & $1.50 \&$ less & 33 & 3.30 & .89 & & \\
\hline \multirow{4}{*}{3.} & \multirow{4}{*}{ Audience \& Instructor } & $3.67-4.00$ & 69 & 3.07 & .89 & \multirow{4}{*}{4.957} & \multirow{4}{*}{.002} \\
\hline & & $3.50-2.67$ & 215 & 3.44 & .87 & & \\
\hline & & $2.50-1.67$ & 168 & 3.50 & .77 & & \\
\hline & & $1.50 \&$ less & 33 & 3.59 & .82 & & \\
\hline
\end{tabular}

The One-Way ANOVA Test for students' perceptions of the three factors according to GPA, as shown in Table 9

As seen, results show significant differences among students based on their GPAs. It was found that the highest GPAs have the least difficulties, while those with the lowest GPAs seem to have the most difficulties.

\subsubsection{Open-ended questions}

As to open-ended question 39, which asked students if they had an unpleasant situation during their oral presentation, 36 students reported that the instructor's interruptions and comments and students' talking and laughing were the most unpleasant experiences they ever had. Fourteen reported having unpleasant experiences as a result of working within a group, while 10 said that once they started the presentation, they forgot everything they wanted to say.

Research question 6 aimed to investigate which one of the factors - "personal traits," "presentation skills," "audience," or "instructor" - has more impact on EFL college students' oral presentations from the students' perspectives. Thus, open-ended question 40 asked students to rearrange the above four factors according to their importance. Interestingly, the most important factor reported was "personal traits" (49.3\%) followed by "oral presentation skills" (42.5\%). Third was "instructor" (33.6\%) and fourth was "audience" (38.9\%).

Students were further provided a space to comment if there were other factors that caused difficulties in oral presentation. A few students reported lack of fluency, lack of confidence, lack of technology-based equipment, lack of a quiet classroom, and lack of time as difficulties.

\subsection{Instructors' Interview}

Instructors $(\mathrm{N}=10)$ were asked what a successful oral presentation is from their point of view and what the most important criteria for assessing students' oral presentation are. Most instructors (60\%) said that knowing the topic of 
the presentation really well contributes greatly to its success, as one of them commented, "It begins with a student being well aware of the topic that [he/she] is going to talk about." Added to that is self-confidence, as reported by one of the instructors: "[W]hen it has been prepared, and when it has been researched well in advance, that enables the students to feel confident." Similarly, when asked about the most important criteria for assessing students' oral presentations, half the instructors said that organization of ideas comes first, whereas $30 \%$ mentioned clarity of voice, fluency, and interest in the topic.

As to research question 7, which asked about the instructors' opinions of the main difficulties that English-major students face during oral presentations, interview questions 2 and 3 were applicable. Question 2 asked instructors about their opinions of the main difficulties that English major students encounter during oral presentation. Instructors' responses varied: $50 \%$ believed that poor language command and lack of experience doing oral presentations were the main obstacles. One of the instructors was quoted as saying, "[T]hey are not used to presentations in high school." Others reported lack of self-confidence $(30 \%)$, organization skills (30\%), and grammatical knowledge (30\%).

As to question 3, "How can a teacher be one of the difficulties students face in oral presentation?," $60 \%$ of the instructors warned that the instructor's attitude could be one of the difficulties students face in oral presentations, and one of the instructors pointed out that "[T] he figure of a teacher in the classroom makes students hesitant and afraid." In particular, when instructors show signs of boredom - for example, looking at their watches-students become more anxious. Instructors believed that a teacher should not play the role of an assessor but of a facilitator providing more encouraging comments that allow students to feel more relaxed. In particular, four instructors pointed out that the greatest obstacle an instructor can pose is constantly interrupting the speaker.

Similarly, interview question 4 answers research question 6 about whether students' responses match with the instructors' perspectives. Thus, instructors were asked to rearrange a set of four factors believed to be some of the difficulties students face in oral presentation based on their importance. Instructors $(60 \%)$ believed that "oral presentation skills" are considered one of the most important difficulties while others (30\%) believed that "personal traits" were the most important. The second most important factor reported was the "instructor" and "personal traits" (40\%). Third place was the "audience" (40\%) and "oral presentation skills" (30\%) and finally, the "audience" (40\%) and the "instructor" (40\%). In sum, teachers agree that "oral presentation skills" is the most important difficulty followed by "personal traits," while students see "personal traits" as most important followed by "presentation skills." However, both perspectives put "audience" in fourth place.

When instructors were asked what they would propose to promote oral presentation assessment in the department (interview question 5), they saw the need for an agreed upon, up-to-date, and clear set of guidelines for assessing oral presentation, while others recommended the use of language labs. Still others suggested the use of oral presentations in most of the department courses.

\section{Conclusions, Implications and Recommendations}

To sum up, results indicate that students experience difficulties with their oral presentation at a medium level. Although the means show a medium level, students still experience a number of difficulties that are mostly related to "personal traits," including students' fear of evaluation, avoidance of the instructor's eyes, and forgetting what they want to say. Significant differences were found among students in their GPAs and nationalities.

Indeed, students see "personal traits" as the most important factor affecting their performances, while teachers see "oral presentation skills" as the most important factor. Students further acknowledge other difficulties such as lack of oral presentation courses, technology-based equipment, a suitable environment, and ample time allowed for the presentation.

These results indicate the need for teachers to provide a more suitable environment for students to conduct their presentations, including encouragement and support. Students should be allowed to choose their own topics, which produces greater comprehension and lowers their anxiety. Students also need to be made aware of the criteria used for assessing their oral performances in order to help them prepare well. More importantly, students need to see a peer's presentation modeled before they give their own. In addition, a unified criterion for assessing oral presentations should be considered, as teachers reported. We recommend that an oral presentation course be included in the pre-service teacher education program to equip students with the necessary skills. More conversation courses, including language labs, should be established in the department to help students develop oral skills. 


\section{References}

Abu El Enein, A.H. (2011). Difficulties encountering English majors in giving academic oral presentations during class at Al-Aqsa University. PhD Thesis, Gaza, Islamic University of Gaza.

Akindele, D. \& Trennepohl, B. (2014). Breaking the culture of silence: Teaching writing and oral presentation skills to Botswana University students. Language, Culture and Curriculum, 21(2), 145-166.

Al-Hebaish, S.M. (2012). The correlation between general self-confidence and academic achievement in the oral presentation course. Theory and Practice in Language Studies, 2(1), 60-65. http://dx.doi.org/10.4304/tpls.2.1.60-65

Al-Issa, A.S. \& Al-Qubtan, R. (2010). Taking the floor: Oral presentations in EFL classrooms. TESOL Journal, 1(2), 227-246. http://dx.doi.org/10.5054/tj.2010.220425

Al-Nouh, A. N.; Taqi, H. \& Abdul-Kareem, M.M. (2014). EFL primary school teachers' attitudes, knowledge and skills in alternative assessment. International Education Studies, 7(5), 68-84. http://dx.doi.org/10.5539/ies.v7n5p68

Alwi, N.F.B. \& Sidhu, G.K. (2013). Oral presentation: Self-perceived competence and actual performance among UiTM Business faculty students. Procedia-Social and Behavioral Sciences, 90, 98-106. http://dx.doi.org/10.1016/j.sbspro.2013.07.070

Chen, L. (2009). A study of EFL graduate students' oral presentation anxiety. Unpublished master thesis, national Chung Cheng University, College of Education, Graduate Institute of the Department of Foreign Languages and Literature.

Chuang, Y. Y. (2009). A study of College EFL Students' affective reactions and attitudes toward types of performance-based oral tests. Journal of Educational Research, 43(2), 55-80.

Chuang, Y. Y. (2010). A study of using Task-based Approach to teach EFL speaking. Journal of National Formosa University, 29(4), 37-52.

Chuang, Y. Y. (2011). The effectiveness of implemented oral activities and instructions in the college EF classroom. Journal of National Formosa University, 30.

Dornyei, Z. \& Kormos, J. (2000). The role of individual and social variables in oral task performance. Language Teaching Research, 4(3), 275-300. http://dx.doi.org/10.1177/136216880000400305

Elliott, J. \& Chong, J.L.Y. (2004). Presentation anxiety: A challenge for some students and a pit of despair for others. Challenging education: Socio-cultural, economic and academic outcomes: Proceedings of the 15th ISANA International Conference, 2004, 30 November-3 December, 2004, Grand Hayatt, Melbourne, Victoria.

Emden, J., V.; \& Becker, L. (2004). Presentation skills for students. Basingstoke: Palgrave Macmillan.

Ercan, I.; Irgil, E.; Sigirli, D.; Ozen, N.S.; \& Kan, I. (2008). Evaluation of anxiety among medical and engineering students by factor analysis. Studia Pychologica, 50(3), 267-275.

Fang-peng, G. \& Dong, Y. (2010). A study on college students' anxiety to spoken English. Canadian Social Science, 6(2), 95-101.

Irvine, L. (2012). Orals ain't orals: The role of prepared oral presentations in the classroom and beyond. How do instruction and feedback practices guide delivery choices? Master Thesis. DipTeach EC (BCAE), BA (UQ), ASDA.

Joughin, G. (2007). Student conceptions of oral presentations. Studies in Higher Education, 32(3), 323-336. http://dx.doi.org/10.1080/03075070701346873

Kitano, K. (2001). Anxiety in the college Japanese language classroom. The Modern Language Journal, 85, 549-566. http://dx.doi.org/10.1111/0026-7902.00125

Lee, G. (2009). Speaking up: Six Korean students' oral participation in class discussions in US graduate seminars. English fir Specific Purposes, 28, 142-156. http://dx.doi.org/10.1016/j.esp.2009.01.007

Leichsenring, A. (2010). What do 1st year Japanese EFL students learn by preparing and presenting a group work oriented oral presentations? Online submission to the Institute of Education Sciences, ED 537529. Retrieved Friday 18th April from http://eric.edu.gov./

Levin, P. \& Topping, G. (2006). Perfect presentations. Berkshire, England: Open University Press. In Irvine, L. Orals 
ain't orals: How instructions and assessment practices affect delivery choices with prepared student oral presentations. Paper presented at the Australian and New Zealand Communication Association Conference, Brisbane.

Liow, J. (2008). Peer assessment in thesis oral presentation. European Journal of Engineering Education, 33(5) (6), 525-537. http://dx.doi.org/10.1080/03043790802564103

Mazdayasna, G. (2012). Objective assessment of oral presentations and EFL learners' speaking development. Sheikhbahaee EFL Journal, 1(1), 23-38.

Morita, N. (2000). Discourse socialization through oral classroom activities in a TESL graduate program. TESOL Quarterly, 34, 279-311. http://dx.doi.org/10.2307/3587953

Munby, I. (2011). The oral presentation: An EFL teachers' toolkit. Studies in Culture, 99, 143-168.

Preuss, D.; Schoofs, D.; Schlotz, W. and Wolf, O. (2010). The stressed student: Influence of written examinations and oral presentations on salivary cortisol concentrations in university students. Stress, 13(3), 221-229. http://dx.doi.org/10.3109/10253890903277579

Quality Assurance Agency (QAA) for Higher Education (2006). Code of practice for the assurance of academic quality and standards in higher education. Section 6 assessment of students September 2006. Mansfield: QAA.

Rababah, G. (2005). Communication problems facing Arab learners of English. Journal of Language \& Learning, 3(1), 180-197.

Radzuan, N.R.M. \& Kaur, S. (2011). Technical oral presentations in English: Qualitative analysis of Malaysian engineering undergraduates' sources of anxiety. Procedia-social and Behavioral Sciences, 29, 1436-1445. http://dx.doi.org/10.1016/j.sbspro.2011.11.383

Sadeqhi, R. (2014) Kuwait Education too far off pace. Retrieved from www.arabtimes.com/NewsDetails on Friday 18th April, 2014. Updated on 18/04/2014.

Subasi, G. (2010). What are the main sources of Turkish EFL students' anxiety in oral practice? Turkish online Journal of Qualitative Inquiry, 1(2), 29-49.

Tahira, M. (2011). English language teaching using the whole student philosophy. M.A. Thesis, the SIT Graduate Institute, Brattleboro, Vermont.

Toumi, H. (2011). Call for focus on Kuwait students' communication skills. Retrieved from www.gulfnews.com/news/gulf/Kuwait

Tuan, T. \& Neomy, S. (2007). Investigating group planning in preparing for oral presentations in an EFL class in Vietnam. RELC Journal, 38(1), 104-124. http://dx.doi.org/10.1177/0033688206076162

Turner, K.; Roberts, L.; Heal, C. \& Wright, L. (2012). Oral presentations as a form of summative assessment in a master's level PGCE module: the student perspective. Assessment \& Evaluation in Higher Education, 38(6), 662-673. http://dx.doi.org/10.1080/02602938.2012.680016

Vitasari, P.; Abdul Wahab, M.; Othman, A. \& Awang, M. (2010). A research for identifying study anxiety sources among university students. International Education Studies, 3(2), 189-196. http://dx.doi.org/10.5539/ies.v3n2p189

Wolfe, A. (2008). Oral presentations in marketing courses: Students' attitudes and self-assessment. Presentation \& Paper published in the proceeding in the Marketing Management Association (MMA) 13th Annual Fall Educators Conference, Louisville, Kentucky.

Zappa-Hollman, S. (2007). Academic presentations across post-secondary contexts: The discourse socialization of non-native English speakers. The Canadian Modern Language Review, 63(4), 455-485. http://dx.doi.org/10.3138/cmlr.63.4.455 